\title{
ENSINAR OU Não ENSINAR SOBRE o USO DE Dicionários nas Aulas de Língua Italiana: EIS a Questĩo
}

\author{
Ròmulo Francisco de Souza *
}

RESUMO: Apresentamos os resultados de uma pesquisa de natureza empírica por meio da qual investigamos a prática de professores de língua italiana como língua adicional, no que diz respeito ao lugar dispensado ao ensino do uso do dicionário em suas aulas. Adotamos, como instrumento de pesquisa, um questionário semi-estruturado, aplicado a grupos aleatórios de professores de italiano, atuantes, respectivamente, no Brasil e na Europa, sobretudo na Itália, cujas respostas foram analisadas a partir de um ponto de vista predominantemente qualitativo. Contamos com um total de 37 (trinta e sete) respondentes, sendo 24 (vinte e quatro) brasileiros e 13 (treze) estrangeiros. Em linhas gerais, observamos que os professores de italiano, respondentes da pesquisa, preocupam-se em ensinar sobre o uso do dicionário em suas aulas, demonstrando uma atitude proativa a esse respeito. Constatamos, ainda, uma tendência, principalmente entre os respondentes brasileiros, a eleger os espaços e tempos típicos dos rituais introdutórios de suas aulas e cursos para abordar o tema.

PALAVRAS-CHAVE: ensino de línguas; língua italiana; dicionário; ensino do uso do dicionário.

ABSTRACT: We present the results of an empirical research about the practice of Italian language teachers as an additional language, with regard to how they manage the teaching of the use of the dictionary in their classes. A semi-structured questionnaire was the research instrument adopted. It was applied to random groups of Italian teachers, respectively, in Brazil and Europe, especially in Italy, whose answers were analyzed under a qualitative point of view. We have the amount of 37 (thirty-seven) respondents: 24 (twenty-four) Brazilians and 13 (thirteen) foreigners. In general, we observe that Italian teachers, respondents of the research, are concerned with teaching about the use

\footnotetext{
* Universidade de São Paulo, São Paulo (Brasil) - romulosouza@usp.br DOI: http://dx.doi.org/10.11606/issn.2238-8281.v0i36p17-36
} 
of the dictionary in their classes, showing a proactive attitude in this regard. We also observed a tendency, especially among Brazilian respondents, to choose the spaces and typical times of the introductory rituals of their classes and courses to address the issue.

KEYWORDS: Language teaching; Italian language; dictionary; teaching of the use of dictionary.

ABSTRACT: Nell'articolo si presentano i risultati di una ricerca empirica sulla pratica degli insegnanti di italiano come lingua straniera, relativa al ruolo assegnato all'insegnamento dell'uso del dizionario nelle lezioni di lingua. Un questionario semi-strutturato è stato lo strumento di ricerca adottato. È stato sottoposto a gruppi, composti in modo aleatorio da insegnanti di lingua italiana che lavorano in Brasile $e$ in Europa, prevalentemente in Italia, le cui risposte sono state analizzate in modo qualitativo. Hanno risposto al questionario 37 informatori: 24 brasiliani e 13 di altre nazionalità. È stato osservato che gli insegnanti di lingua italiana includono l'insegnamento dell'uso del dizionario nelle loro lezioni di lingua, rivelando un comportamento proattivo. Soprattutto tra gli insegnanti brasiliani, è stata notata una tendenza a scegliere spazi e tempi tipici dei rituali introduttivi delle loro lezioni e dei corsi per affrontare l'argomento.

PAROLE CHIAVE: insegnamento delle lingue straniere; lingua italiana; dizionario; insegnamento dell'uso del dizionario 


\section{Introdução}

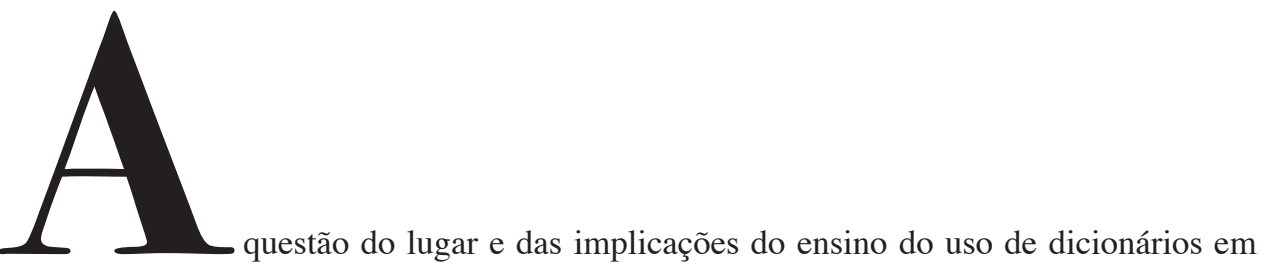

sala de aula, seus formatos e possíveis contribuições para aquisição de línguas adicionais, vem sendo discutida, investigada e descrita por meio de pesquisas formais há, pelo menos, quase um século, segundo levantamento de Welker (2006). Não obstante, parece ainda existir uma carência de investigações empíricas sobre o tema. Nas palavras do lexicógrafo: "muitos autores falam da necessidade de se ensinar o uso de dicionários, mas existem pouquíssimas pesquisas empíricas sobre esse assunto" (WELKER, 2006, p. 20).

Atkins e Knowles (1990), Chi (1998) e Muller (2002) apresentam pesquisas de natureza quantitativa cujos resultados podem sugerir práticas em que o ensino sobre o uso do dicionário se mostra ausente do contexto de ensino e aprendizagem de inglês como língua adicional, ainda que seja considerado de grande relevância para o processo de aprendizagem de idiomas pelos docentes.

A investigação de Atkins \& Knowles (1990), por exemplo, mostrou que $75 \%$ dos aproximadamente 740 (setecentos e quarenta) aprendizes europeus, respondentes da pesquisa, usam o dicionário bilíngue, sendo que $60 \%$ deles relataram não ter recebido instrução sobre o uso dessa ferramenta. Em termos mais específicos, o estudo mostrou que $60,4 \%$ dos aproximadamente 740 respondentes nunca receberam instrução sobre o uso do dicionário; 26,7\% receberam alguma instrução, mas nada preciso ou sistematizado; e somente 12,9\% tiveram instruções precisas e sistematizadas (ATKINS; KNOWLES, 1990, p. 385). A pesquisa de Chi (1998, p. 573), por sua vez, mostrou que 68\% dos 67 (sessenta e sete) estudantes chineses de Inglês como língua adicional, respondentes de sua pesquisa, afirmaram nunca ter recebido instruções formais sobre o uso do dicionário. Muller (2002), enfim, relatando um estudo realizado em 1997, entre professores atuantes no Rio Grande do Sul, observou que, embora 94\% dos 38 (trinta e oito) docentes entrevistados afirmem considerar importante o ensino sobre o uso do dicionário em sala de aula, apenas 14\% dizem organizar atividades com essa ferramenta.

Os cenários apresentados em Atkins e Knowles (1990), Chi (1998) e Muller (2002) vão ao encontro da percepção de Waring (2001), o qual também conclui que muitos professores compreendem a necessidade do ensino de habilidades de consulta ao dicionário, mas não o fazem em sala de aula. O autor amplia o diálogo apontando e discutindo pelo menos 6 (seis) 
justificativas para essa atitude (Quadro 1).

Quadro 1 - Justificativas para não ensinar sobre o uso de dicionário (WARING, 2001) ${ }^{1}$

- Muitos professores pressupõem que seus estudantes saberão usar o dicionário monolíngue da língua-alvo com eficiência, uma vez eles já sabem usar bem o dicionário monolíngue da língua materna;

- muitos professores temem que os aprendizes terão resistência ao dicionário monolíngue da língua-alvo, ficando dependentes do dicionário bilíngue. Se isso ocorrer, sentirão seus esforços desperdiçados, já que convencer os estudantes a usar um dicionário monolíngue exige tempo e comprometimento por parte do professor e do aluno;

- o trabalho com o dicionário não é parte do programa do curso;

- o trabalho com o dicionário não é considerado interessante;

- os professores não têm uma compreensão clara a respeito do dicionário ou sobre como apresentar um dicionário monolíngue na língua-alvo;

- os estudantes não possuem, todos, o mesmo dicionário monolíngue da línguaalvo, o que torna o exercício problemático.

Frente a esse contexto e cenários, a pergunta que fazemos e que motiva este trabalho é: como os professores do início do século XXI, de língua italiana como língua adicional, posicionam-se a respeito do ensino do uso de dicionários? E mais: há lugar para essa prática pedagógica em suas aulas? Se sim, qual é esse lugar? O uso do dicionário é valorizado ou desvalorizado? Se é valorizado, quais estratégias são adotadas no sentido de ensinar a respeito desse uso? Se é desvalorizado, por que isso acontece? Existe diferença entre a prática dos professores brasileiros e a dos professores estrangeiros ${ }^{2}$ de língua italiana como língua adicional no que se refere a esse tema?

Cabe ressaltar que não é nossa intenção oferecer conclusões definitivas, mas contribuir com pesquisas empíricas sobre o tema, motivar novas investigações e indicar possíveis caminhos para os educadores que desejem empreender esforços pedagógicos visando ao ensino sobre o uso de dicionários em suas aulas de língua.

Dessa forma, nas seções 2 e 3, apresentamos nossa revisão de literatura abordando temas que consideramos fundamentais para a compreensão do nosso objeto de pesquisa. Na seção 2 , trazemos uma série de estudos e opiniões que versam sobre os prós e os contras do ensino do uso de dicionários nas aulas de línguas adicionais. Na seção 3, trazemos reflexões sobre o aspecto pedagógico relacionado a essa prática. Nas seções 4 e 5, respectivamente, apresentamos

1 Tradução nossa.

2 Neste texto, consideramos professores estrangeiros em oposição a brasileiros. 
a metodologia e os resultados de nossa investigação.

\section{Prós e contras sobre o uso do dicionário no ensino de línguas adicionais}

O uso do dicionário em sala de aula de língua estrangeira não é um ponto pacífico entre professores, educadores, linguistas e linguistas aplicados. Trata-se, de fato, conforme Hudson (2007), de um tema que pode esquentar os ânimos dos professores, dividindo-os entre aqueles que o enxergam como algo a ser evitado a qualquer custo em sala de aula e aqueles que o consideram o elemento mais importante do processo de aprendizagem de línguas. Nesta seção, buscamos compreender melhor a questão, abordando estudos e opiniões que podem representar essa diversidade de visões sobre o uso dos dicionários no ensino e aprendizagem de línguas.

Um olhar panorâmico a partir de uma perspectiva histórica a respeito das diversas abordagens e métodos de ensino de línguas estrangeiras, principalmente no ocidente, indicará, de forma geral, que o uso do dicionário no ensino e aprendizagem de línguas foi ora valorizado, ora desvalorizado, de acordo com a perspectiva teórica predominante. Dessa forma, o método baseado em gramática e tradução (RICHARDS; RODGERS, 2001; LARSEN-FRREMAN, 2004), por exemplo, tende a valorizar o uso do dicionário bilíngue. Ao contrário, propostas que, de alguma forma, se opõem a esse método, e que buscam a centralidade do aprendiz, como os métodos diretos, tendem a desvalorizar o uso desse artefato, como apontam Corda \& Marello (2004).

Podemos relacionar a questão do uso do dicionário em sala de aula a pesquisas que tentam observar os efeitos do uso desse instrumento na aprendizagem de línguas (WELKER, 2006; HUDSON, 2007). Investigações nesse sentido, entretanto, são poucas e apresentam resultados contraditórios, como observam Corda e Marello (2004, p. 83):

São poucos os estudos conduzidos sobre a influência que o emprego do dicionário pode ter sobre os resultados alcançados pelos estudantes (...) em tarefas de compreensão, em tarefas de produção/tradução. (...) em alguns casos, o acesso ao dicionário parece ter efeitos positivos; em outros, efeitos nulos ou, até mesmo, negativos. (CORDA; MARELLO, 2004, p. 83) ${ }^{3}$.

A utilização do dicionário pode ser questionada quando se trata do ensino de habilidades específicas, tais como a leitura e a produção escrita. A esse respeito, Fromm (2003, p. 7) não recomenda o uso do dicionário quando o objetivo da atividade de produção escrita é avaliativo ou quando, em atividades de leitura, espera-se que o aprendiz leia sem auxílio do dicionário. Segundo o pesquisador:

Devemos ter em mente que o dicionário é uma ferramenta auxiliar no processo de ensino. Essa ferramenta, entretanto, nem sempre deve ser usada. Quando

3 Tradução nossa. 
avaliamos o aluno por meio de uma redação, desejamos verificar, entre outras coisas, a quantidade de itens lexicais de que o mesmo dispõe. Se o deixarmos usar o dicionário, essa verificação não será possível. (...) Uma aula de língua instrumental para leitura também representa uma armadilha quanto ao uso do dicionário. Nesse tipo de ambiente são ensinadas técnicas que descartam o uso do mesmo. Ceder às pressões (inevitáveis) dos alunos para usá-lo pode resultar numa perda total dos objetivos propostos. (FROMM, 2003, p. 7).

Concordamos com Fromm (2003, p. 7) no que diz respeito aos dois casos. Acrescentamos que cabe ao professor determinar, com clareza, se a sua proposta de produção escrita tem como meta contribuir para a ampliação do vocabulário, por parte do aprendiz, ou promover avaliação de sua aprendizagem, que pode ser focada em itens como o seu universo lexical ou a sua capacidade estratégica em situações de produção escrita. Citamos, como exemplo, a capacidade de utilizar estratégias de compensação em situações comunicativas que envolvem a escrita, lançando mão de paráfrases e/ou sinônimos que sustentem sua intenção comunicativa (WIDDOWSON, 1991). Estratégias de compensação, vale lembrar, ajudam o aprendiz a utilizar a língua, superando a sua falta de conhecimento sobre ela. Além da utilização de paráfrases e sinônimos, são também exemplos desse tipo de estratégia, segundo Oxford (1990), a adivinhação inteligente embasada no contexto e o esquivamento de um tópico.

No caso da leitura, compreendemos que Fromm (2003, p. 7) se refere ao desenvolvimento de estratégias mistas, ou seja, que exploram processos ascendentes e descendentes (DELL'ISOLA, 2000; MATLIN, 2004; HUDSON, 2007), tais como: a construção de inferências a partir do contexto ou do conhecimento prévio do leitor; o reconhecimento e o uso de pistas textuais, de natureza morfológica, sintática, discursiva, não verbal, relativa ao gênero textual etc.; e o uso de estratégias de compensação, durante o processo de compreensão. Dessa forma, se pressupormos que o objetivo pedagógico é o de auxiliar o aprendiz no desenvolvimento de sua capacidade leitora, bem como de sua autonomia nessa tarefa, o uso do dicionário deverá ser evitado em alguns momentos.

Consoantes com essa perspectiva, estão também Corda e Marello (2004), quando afirmam que, para a compreensão de textos, o papel do dicionário será, principalmente, o de instrumento de verificação de hipóteses, e Finger-Kratochvil e Carvalho (2016), quando, por sua vez, apontam a consulta ao dicionário como a última estratégia de aquisição lexical a se lançar mão no processo de construção do significado de palavras durante a leitura. Tal ação, de fato, segundo as autoras, deveria ser empregada somente após as tentativas de compreensão lexical a partir do contexto e da análise dos aspectos morfológicos da língua alvo. Em suas palavras:

As principais estratégias de aquisição lexical são: o uso do contexto, da morfologia e do dicionário. Quando as duas primeiras não dão conta de atender as necessidades de construção de significado da palavra, o leitor precisa avaliar se a palavra é crucial para sua compreensão do texto. Se for, 
ele precisará valer-se de uma fonte especializada como obras de referência e dicionários. Dentre as estratégias mencionadas, o dicionário tem sido sugerido como última estratégia a se recorrer, por ser a que mais demanda tempo e interrompe o fluxo de leitura. Por isso, antes de utilizá-lo, recomendase ao leitor avaliar o que não ficou claro, e qual a importância desse item lexical para construir um sentido para o texto. (FINGER-KRATOCHVIL E CARVALHO, 2016, p. 298).

Finger-Kratochvil e Carvalho (2016) observam ainda que a interrupção do fluxo de leitura para a consulta ao dicionário não é necessariamente prejudicial, desde que sejam feitas em momentos oportunos e com uma frequência não muito alta. Leffa $(2006 ; 2011)$ argumenta, nesse sentido, que será importante para o leitor a capacidade de não perder de vista o contexto em que a palavra se encontra, no texto, para que a consulta ao dicionário seja bem sucedida. O leitor deverá compreender se a palavra consultada se encaixa naquele contexto. Trata-se, o uso do dicionário, para os autores, de um recurso importante, cuja adequada utilização pode contribuir positivamente para o processo de desenvolvimento da compreensão leitora, desde que utilizado adequadamente.

Os debates de Finger-Kratochvil e Carvalho (2016) sobre o uso do dicionário apontam para a questão do papel do vocabulário no processo de compreensão leitora. A esse respeito, Schmitt et al (2001) e as próprias Finger-Kratochvil e Carvalho (2016) concordam que, de fato, inúmeras pesquisas têm confirmado a percepção de educadores e professores de idiomas de que o conhecimento de vocabulário e o desempenho durante a leitura são fatores estritamente correlacionados. Para Finger-Kratochvil e Carvalho (2016), leitores que tem um vocabulário reduzido apresentam maiores dificuldades na leitura, necessitando despender mais tempo e energia cognitiva para a realização da tarefa.

Koda (2004), por sua vez, defende a pouca existência de consenso na literatura em L2 "a respeito de quais elementos (...) devem ser considerados no entendimento da relação entre conhecimento de vocabulário e compreensão, entre os leitores de segundas línguas" (KODA, 2004, p. 58). A autora lembra que a questão pode ser abordada a partir de, pelo menos, dois pontos de vista, ou seja, do vocabulário como suporte à compreensão ou como elemento inserido em uma relação de interdependência com ela.

No primeiro caso, entra em jogo o conceito de limiar de vocabulário, ou seja, a noção de que seria necessário conhecer uma certa porcentagem de palavras de um texto para que se possa compreendê-lo. Koda (2004) cita, por exemplo, as pesquisas de Hu e Nation (2000) e Carver $(1994,2000)$, as quais apontam, respectivamente, para a necessidade de se conhecer em torno de $98 \%$ e $99 \%$ das palavras de um texto para compreendê-lo adequadamente, sem o auxílio de dicionários ou outro tipo de assistência.

No segundo caso, considera-se a noção de que o significado de uma palavra será estabelecido pelo leitor de acordo com o contexto em que aparece, dada a sua natural polissemia. Uma 
palavra como lar, por exemplo, como explica Koda (2004), pode evocar imagens que vão desde uma mansão até um barraco de lona para o leitor, quando descontextualizada, de acordo com a sua experiência de vida e seus conhecimentos prévios. Uma vez estabelecido o contexto, esse leitor poderá definir e, portanto, compreender o conceito de lar relacionado ao texto.

Koda (2004) defende ainda que tais perspectivas não devem ser percebidas como excludentes entre si, uma vez que ambas, quando vistas em conjunto, parecem representar aspectos pertinentes às diferentes formas de interação entre conhecimento de vocabulário e leitura, além de explicar como os vários modos de aprendizagem podem contribuir para esse processo. De fato, enquanto o primeiro aspecto traz à tona a importância de se conhecer um universo vocabular básico para obter sucesso na compreensão leitora, o segundo aponta para a concepção de que a aprendizagem de vocabulário se dá também a partir da própria leitura e será contínua ao longo da vida do leitor-aprendiz (KODA, 2004).

Pesquisas que destacam o uso do dicionário como atividade essencial para a aprendizagem do vocabulário são as de Zucchi (2010) e Luppescu e Day (1993). De cunho quantitativo, experimental, ambas apresentam resultados estatísticos significativos que mostram que, entre os seus respondentes, estudantes de italiano e inglês como língua adicional, respectivamente, aqueles que utilizaram o dicionário, bilíngue ou monolíngue, tiveram maior sucesso na compreensão de itens lexicais, em comparação com aqueles que não utilizaram qualquer tipo de dicionário. Enquanto Zucchi (2010) orientou sua pesquisa pela hipótese de que o contexto não seria suficiente para a adequada compreensão de vocabulário na atividade de leitura, Luppescu e Day (1993) pretendiam confirmar que não haveria diferença significativa, em termos numéricos, entre o vocabulário aprendido por estudantes que utilizam dicionário bilíngue e estudantes que não utilizam qualquer dicionário e, ainda, que aqueles demorariam mais tempo na leitura do que esses.

Concluímos esta seção trazendo a contribuição de Waring (2001). O autor, tendo como foco o contexto de ensino de inglês como língua adicional no Japão, aponta 8 (oito) razões favoráveis ao ensino de habilidades de consulta ao dicionário. Reunimo-nas no Quadro/ 2. 
Quadro 2 - Razões para o ensino de habilidades de consulta ao dicionário (WARING, 2001, p. 1) ${ }^{4}$

- Desenvolver habilidades de consulta ao dicionário dará aos aprendizes maior controle sobre a própria aprendizagem, o que atribui a responsabilidade da aprendizagem para o aluno;

- não se nasce sabendo como usar bem o dicionário; por isso, o aprendiz precisa desenvolver o conhecimento e as habilidades para conseguir resultados eficientes com essa ferramenta;

- desenvolver habilidades de consulta ajuda os estudantes a distinguir informações no dicionário, porque torna as informações mais explicitas para eles;

- o dicionário naturalmente dá muito o que pensar a respeito de língua e significação;

- se os aprendizes souberem usar bem o dicionário, haverá um mínimo de interrupções em sala, porque o professor confiará que os aprendizes saberão encontrar e escolher o significado correto;

- dicionários podem fornecer um suporte útil não wapenas quando o professor está em dúvida sobre algo, mas quando quiserem que seus alunos confirmem as suas próprias hipóteses com relação à língua-alvo;

- o dicionário pode servir como argumento para comunicação e interação em sala de aula;

- a prática do uso do dicionário pode ajudar os aprendizes a explorar preferências pessoais e estilos de aprendizagem e pode, também, conduzir os estudantes a novas formas de estudo.

Entre os pontos positivos sobre o ensino do uso do dicionário, apontados por Waring (2001), destacamos a contribuição para o desenvolvimento da autonomia dos aprendizes, a possibilidade de incentivar a reflexão sobre a língua, o apoio ao processo de ensino e aprendizagem, não apenas em sala de aula, mas também fora dela, e a possibilidade de personalização do ensino.

\section{Ensino e aprendizagem do uso de dicionários: reflexões sobre o aspecto pedagógico}

Nesta seção, abordamos a questão do ensino do uso dos dicionários tanto do ponto de vista do professor - suas estratégias, técnicas e métodos -, quanto do ponto de vista do aprendiz, ou seja, as habilidades de consulta a serem desenvolvidas visando ao uso adequado dessa ferramenta. Consideramos que ambas as dimensões estão intrinsecamente associadas, já que pres-

4 Tradução nossa. 
supomos que o objetivo de qualquer ação didática empreendida pelos educadores (produção de material didático, elaboração de atividades ou sequências didáticas, feedbacks reativos ou instruções em geral, entre outras), visando desenvolver as habilidades de consulta ao dicionário, deverá considerar, e discernir com clareza, a natureza e a adequação de tais habilidades. Compreendemos como habilidades de consulta, ou reference skills, em acordo com Welker (2006), "as habilidades que os usuários precisam possuir para poderem aproveitar as informações oferecidas em obras de referência, no nosso caso, em dicionários” (WELKER, 2006, p. 36).

A leitura da introdução de dicionários é uma estratégia produtiva e amplamente recomendada, uma vez que, geralmente, é naquela seção da obra que o leitor encontrará informações sobre as suas características e funcionamento (BISHOP, 2000). Segundo Corda \& Marello (2004), contudo, não é suficiente apenas aconselhar essa leitura em sala de aula. As autoras apontam para ações pedagógicas direcionadas e abrangentes, quando lembram que os estudantes precisam adquirir familiaridade com a estrutura do dicionário, sua metalinguagem e o seu funcionamento; reconhecer, com clareza, os significados das suas abreviações e de seus símbolos; desenvolver determinadas estratégias, de acordo com a tarefa que pretendem cumprir ao consultá-lo. Elas recomendam que as instruções sobre o uso do dicionário sejam associadas a uma determinada tarefa (tais como produção de texto, leitura ou tradução), sendo, ainda melhor, se forem integradas.

Essa parece ter sido a opção de Chi (1998), Cubillo (2002) - também analisados em Corda e Marello (2004) - e Carduner (2003). Chi (1998, p. 577) propõe a integração de atividades relacionadas ao uso do dicionário ao conteúdo programático de um curso de escrita de relatórios científicos para um grupo de estudantes universitários de inglês avançado. $\mathrm{O}$ autor optou por priorizar instruções diretas e expositivas sobre o dicionário, reservando apenas a quinta aula para exercícios práticos de consulta (ANEXO I).

Cubillo (2002, p. 206), por sua vez, apresenta uma proposta de ensino sobre uso de dicionários baseada em projetos. A pesquisadora abdica de instruções específicas sobre a consulta a dicionários, propondo a seus alunos de Inglês - estudantes universitários de Química - a elaboração dos seus próprios dicionários, os quais seriam compostos por palavras encontradas nos textos técnicos lidos durante o curso, correspondendo também às suas próprias necessidades. A autora acrescenta que o projeto foi bem recebido pelos aprendizes, trazendo-lhes motivação real para sua confecção e ajudando-lhes a estudar para os próprios exames (CUBILLO, 2002, p. 224). Eles puderam perceber as relações entre as palavras do texto e o modo como o contexto afeta os significados, além de adquirir maior familiaridade com as estruturas dos dicionários e perceber a existência de informações, que até então desconheciam, sobre obras de referência (CUBILLO, 2002, p. 224). A sua opção por uma experiência personalizada de aprendizagem sobre o uso de dicionários aparece como uma tentativa de corresponder às dificuldades pedagógicas que se apresentam, principalmente em turmas numerosas, perante o pressuposto de que se tornar um usuário competente desse instrumento envolve saber utilizar não apenas um dicionário, mas dicionários em geral; saber utilizar as informações encontradas no dicionário, 
percebendo como elas podem ser úteis na resolução das demandas individuais; considerar o contexto de uso, a seleção e o design dos dicionários (CUBILLO, 2002, p. 208).

Carduner (2003, p. 71), enfim, propõe a integração do ensino do uso de dicionários ao conteúdo programático de um curso de produção escrita e estudo da gramática de base do espanhol como língua adicional, de modo que se alinhe aos seus objetivos e contribua, também, para o desenvolvimento da autonomia dos aprendizes. Considerando os objetivos desse curso, Carduner (2003) compreende que as habilidades de consulta aos livros de referência serão mais úteis aos aprendizes, em comparação com as estratégias de memorização de palavras e de regras gramaticais. O autor aponta seis objetivos relativos ao desenvolvimento das habilidades de consulta condizentes com essa perspectiva:

1. Desfazer a síndrome da palavra isolada, ou seja, mostrar para os aprendizes que tradução palavra por palavra, geralmente, não se mostra eficaz para a compreensão;

2. mostrar para os aprendizes a relação entre habilidades de consulta a obras de referência e as atividades de escrita, revisão e edição;

3. mostrar para os aprendizes a relação entre conhecer as categorias gramaticais e ser capaz de localizar informações linguísticas;

4. familiarizar os aprendizes com os pontos fracos e os pontos fortes dos livros de referência, considerando a grande variedade desse tipo de obra;

5. promover o desenvolvimento de estratégias - localização de entradas do dicionário, uso de abreviações, verificações cruzadas ou consulta a fontes alternativas - visando a precisa seleção de vocabulário;

6. mostrar aos aprendizes que os dicionários não contem apenas informações lexicais, mas também gramaticais.

(CARDUNER, 2003, p. 71) .

Carduner (2003) mostra as possibilidades de integração entre o ensino do uso do dicionário e o conteúdo programático do curso lembrando que, durante a unidade sobre substantivos, por exemplo, os alunos aprendem a localizar e identificar as formas de gênero e flexão dos substantivos no dicionário. Em uma aula sobre verbos, eles aprendem a localizar e trabalhar com quadros de conjugação verbal, que geralmente aparecem nesse tipo de obra.

Béjoint (1994; 2000 apud WELKER, 2006) também versa sobre a questão das habilidades necessárias à consulta ao dicionário. Conforme nos lembra Welker (2006), o autor elenca pelo menos 7 (sete) habilidades relacionadas a diversas situações de uso. Reunimo-nas no Quadro 3.

5 Tradução nossa. 
Quadro 3 - Operações necessárias à consulta de dicionários (BÉJOINT, 1994 apud WELKER, 2006, p. 37).

1. Escolher o dicionário adequado/apropriado, de acordo com o problema;

2. identificar o item lexical problemático;

3. determinar o lugar mais provável do dicionário em que o item lexical possa ser tratado;

4. adivinhar a forma em que a palavra está registrada (a forma do lema);

5. adivinhar onde o item aparece na ordem alfabética (por exemplo: nomes próprios ou abreviaturas podem estar em apêndices);

6. encontrar a palavra enquanto lema ou sublema, ou encontrá-la dentro de um verbete ou subverbete; isso pode implicar que se precise escolher entre homógrafos e utilizar informações sintáticas ou semânticas;

7. interpretar a informação dada no verbete; isso pode significar que se precise interpretar:

- informações sobre a ortografia: de formas derivadas ou conjugadas, do plural, do comparativo, de verbos irregulares, informação sobre a divisão silábica, etc.;

- informações sobre a pronúncia: sons, posição do acento etc.;

- informações sobre variedades linguísticas: marcas de uso;

- informações sobre a sintaxe: classe gramatical, posição do adjetivo, aspecto contável ou incontável dos substantivos, escolha da preposição etc.;

- informações sobre o significado: sinônimos e antônimos, hiperônimos e hipônimos em diversos tipos de definições, outros tipos de relações semânticas, exemplos, citações, ilustrações pictóricas, significados figurados, etc.; e

- informações sobre a história da palavra: etimologia.

Dias [s.d.] propõe uma sequência didática sobre o uso de dicionários bilíngues em um contexto de ensino de Inglês como língua estrangeira. A sua atividade busca trabalhar o desenvolvimento das seguintes habilidades de consulta: 1) organização do dicionário: ordem alfabética; 2) localização de palavras; e 3) tipos de informações encontradas no dicionário: busca pelo significado das abreviações, pela leitura da introdução do dicionário; busca por significados de palavras.

A sequência de Dias [s.d.] conta, ainda, com: 1) a exposição de algumas regras para o uso do dicionário; 2) noções relativas a macroestrutura e a microestrutura; ex.: lematização (gênero dos substantivos; infinitivo do verbo; grau do adjetivo); organização das entradas, considerando fenômenos de homonímia; presença de especificações a respeito de variantes da língua, etc.; e 3) noções sobre tipos de dicionários e sua caracterização geral.

A partir dos pontos de vistas, opiniões e práticas debatidas nesta seção, podemos concluir 
que são inúmeras as possibilidades de metodologia empregadas no ensino do uso de dicionários. No entanto, todas elas deverão considerar as habilidades de consulta necessárias para uma utilização efetiva do dicionário.

\section{Metodologia}

A pesquisa que apresentamos é de cunho qualitativo (BROWN; RODGERS, 2002), de natureza empírica, envolvendo o uso de dicionários (WELKER, 2006). Segundo Brown e Rodgers (2002), pesquisas qualitativas, ao contrário das quantitativas, são predominantemente baseadas em dados não-numéricos. Strauss e Corbin (2008), por sua vez, observam que a quantificação de dados, em pesquisas qualitativas, como no caso do censo ou informações históricas sobre pessoas ou objetos estudados, não altera o caráter qualitativo quando o grosso da análise é interpretativo. Os autores citam como técnicas tipicamente qualitativas, entre outras, as observações ou notas de campo, os diários de bordo produzidos pelos pesquisadores, os questionários e as entrevistas. A respeito de pesquisas empíricas envolvendo dicionários, Welker (2006) aponta, entre outros, os questionários, os testes, os protocolos de uso, as entrevistas e a observação direta, como métodos comumente utilizadas em pesquisas empíricas envolvendo o uso desse artefato.

Os dados que apresentamos foram obtidos por meio de questionário semi-estruturado, ou seja, composto por questões abertas e fechadas. A escolha desse modelo, coerente com o nosso objeto de estudo e com nossos objetivos de pesquisa, permitiu-nos uma análise de teor predominante qualitativo, envolvendo, também, aspectos de ordem numérica, quando pertinente, no sentido de alcançarmos nossas metas.

Lançamos mão do questionário com o objetivo de investigar a prática e o posicionamento de professores de língua italiana como língua adicional, no que diz respeito ao ensino do uso do dicionário em suas aulas. Esperávamos, dessa maneira, obter subsídios para tentar responder as questões que motivaram esta pesquisa, anunciadas na introdução deste trabalho, a saber:

- Como os professores de italiano como língua adicional se posicionam a respeito do ensino do uso de dicionários?

- Há lugar para essa prática pedagógica em suas aulas? Qual é esse lugar?

- O uso do dicionário é valorizado ou desvalorizado? Se for valorizado, quais estratégias são adotadas no sentido de ensinar a respeito desse uso? Se for desvalorizado, por que isso acontece?

- Existe diferença entre a prática dos professores brasileiros e a dos professores estrangeiros no que diz respeito a esse tema?

O questionário foi aplicado a grupos aleatórios de professores de italiano como língua adicional, alcançando um total aproximado de 100 professores em exercício no biênio 2011/2012. 
Desse total, obtivemos resposta de 37, sendo 24 (vinte e quatro) brasileiros, que atuam no Brasil, e 13 (treze) estrangeiros, que lecionam na Europa, predominantemente na Itália.

\section{Resultados da pesquisa}

Organizamos os resultados da pesquisa em 5 (cinco) grandes eixos, os quais reunimos e apresentamos nesta seção. Eles trazem o posicionamento dos professores respondentes no que se refere à opção por ensinar ou não ensinar sobre o uso de dicionários nas aulas de italiano como língua adicional (seção 5.1); à sua justificativa para abordar ou não abordar esse tema (seções 5.2 e 5.3); às técnicas e estratégias de ensino (seção 5.4), bem como ao momento da aula (seção 5.5), que consideram mais adequados para o ensino sobre o uso dessa obra de referência em suas aulas ou cursos, quando o fazem.

\subsection{Da opção por ensinar ou não sobre o uso dos dicionários}

Conforme mencionamos, a nossa pesquisa contou com um total de 37 (trinta e sete) respondentes, professores de italiano como língua adicional, sendo 24 (vinte e quatro) brasileiros, que atuam no Brasil, e 13 (treze) estrangeiros, que ensinam na Europa, predominantemente na Itália. Entre os brasileiros, 58\% afirmaram ensinar sobre o uso de dicionários em suas aulas. Os outros $42 \%$ desse público declararam não adotar essa prática. Com relação aos professores estrangeiros, $77 \%$ afirmaram que sim, dedicam tempo de sua aula para o ensino sobre o uso de dicionários, enquanto os outros $23 \%$ declararam que não o fazem. O GRÁFICO 1 mostra esses resultados, em termos percentuais.

Gráfico 1 - Ensino do uso de dicionário em sala de aula de italiano como língua adicional

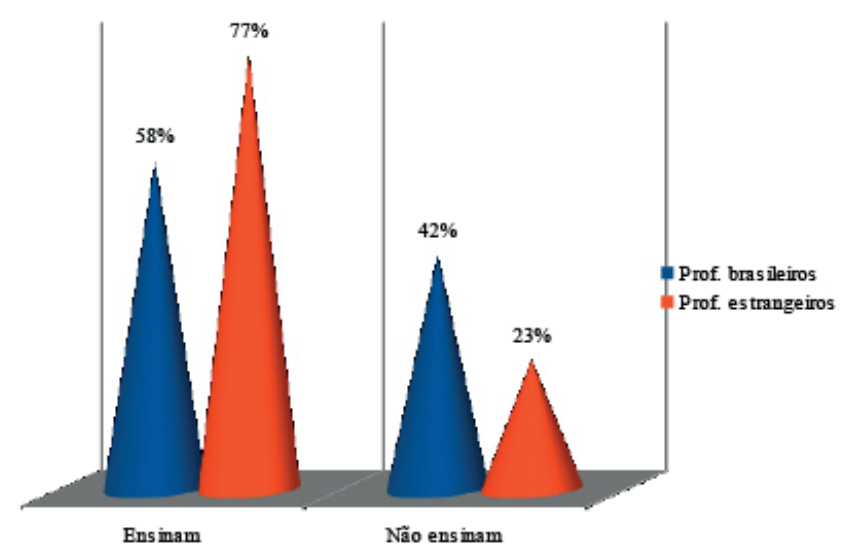


A partir desses dados, percebemos que o ensino do uso dos dicionários está presente na prática desses professores. De fato, a maioria dos respondentes da pesquisa declarou ensinar sobre o uso desse recurso em suas aulas de língua italiana como língua adicional.

\subsection{Dos motivos para não ensinar sobre o uso de dicionários}

Os professores brasileiros que disseram não ensinar sobre o uso dos dicionários em suas aulas de língua italiana declararam adotar essa postura por 5 (cinco) motivos: 1) por priorizar outros conteúdos; 2) por temer que o dicionário se transforme em uma muleta para os estudantes; 3 ) por considerar ou saber que os seus alunos sabem usar o dicionário com sucesso; 4) por considerar suas aulas muito curtas; e 5) por desconhecer essa possibilidade (declaram não ter considerado essa hipótese).

Os professores estrangeiros, por sua vez, declararam que não o fazem por 2 (dois) motivos: 1) porque consideram que o perfil dos cursos em que lecionam não demandam tal prática, por se tratar de cursos focados na oralidade, referindo-se a cursos intensivos do programa ERASMUS (ERASMUS PROGRAMME); e 2) porque acreditam que o dicionário não é uma ferramenta essencial para a aprendizagem de uma língua estrangeira, sendo preferível fazer com que os aprendizes cheguem as definições sem o auxílio dessa ferramenta.

\subsection{Dos motivos para ensinar sobre o uso de dicionários}

Os professores brasileiros que declararam ensinar sobre o uso do dicionário o fazem por dois motivos: 1) por considerar o dicionário uma ferramenta essencial no processo de ensino e aprendizagem de uma língua adicional; e 2) por perceber dificuldades de consulta e compreensão do funcionamento dos dicionários por parte dos seus alunos. Nesse caso, foram citadas dificuldades relativas à falta de costume com a lematização das palavras do italiano, tais como verbos pronominais e nomes no plural, e ao desconhecimento dos termos técnicos do dicionário.

Os professores estrangeiros, por sua vez, que adotam a prática do ensino sobre o uso dos dicionários, fazem-no por 3 (três) motivos: 1) por considerar a consulta ao dicionário uma habilidade técnica que todos os estudantes de línguas devem possuir; 2) por se preocupar com o desenvolvimento da autonomia dos alunos no que diz respeito ao uso de seus instrumentos de trabalho, referindo-se aos estudantes de cursos de graduação em línguas; e 3) por considerar o dicionário uma ferramenta e uma fonte importante do processo de ensino e aprendizagem de línguas.

\subsection{Das técnicas e estratégias de ensino do uso de dicionários}

Os professores respondentes brasileiros declararam adotar as seguintes estratégias de en- 
sino sobre o uso de dicionários: 1) leitura da introdução do dicionário; 2) explanação sobre o funcionamento do dicionário (ex.: circularidade) e sobre seus elementos constitutivos (ex.: abreviações, acentos gráficos, etc.); 3) explanação sobre os diferentes tipos de dicionários existentes (bilíngue, monolíngue, híbrido); e 4) explicações teóricas sobre o funcionamento do dicionário e de seus elementos principais, associado à prática por meio de busca de palavras a partir de listas pré-selecionadas pelo professor.

Os professores estrangeiros, por sua vez, citaram as seguintes estratégias: 1) prática por meio de perguntas dirigidas, com o objetivo de consultar o dicionário para responder questões específicas sobre esse instrumento (ex.: definir o gênero de uma palavra, consultando o dicionário); 2) jogos com dicionários; 3) explanações sobre a estrutura do dicionário; 4) explanações que instrumentalizam o aluno a partir de mecanismos morfológicos da língua italiana (ex.: como chegar à forma lematizada de cada categoria de palavras; noções de prefixação e sufixação; explicações sobre as origens de uma palavra, no sentido de determinar que não se trata de uma palavra italiana).

\subsection{Do momento reservado para o ensino do uso de dicionários}

Os professores brasileiros apontaram 6 (seis) momentos relacionados ao ensino sobre o uso do dicionário. São eles: 1 ) a primeira vez que é levado em sala ${ }^{6}$; 2 ) quando inicia uma nova turma; 3) no início do semestre, em uma aula específica; 4) nas aulas iniciais do curso; 5) durante o curso, antes de leituras; e 6) quando surgem dúvidas sobre o uso do dicionário.

Os professores estrangeiros, por sua vez, apontaram 3 (três) momentos: 1) quando surge a necessidade, durante a aula; 2) no fim da aula; e 3) não há um momento específico.

A partir da análise dos dados relativos ao momento reservado para o ensino do uso dos dicionários, podemos estabelecer dois tipos de abordagem. Classificamos o primeiro tipo de proativo, ou seja, caracterizado pela ação espontânea e premeditada do professor de mobilizar esforços pedagógicos visando ao ensino e à aprendizagem sobre o uso do dicionário, e, o segundo tipo, de reativo, quando a intervenção pedagógica está condicionada a demandas circunstanciais, como, por exemplo, o surgimento de dúvidas sobre o assunto.

Os professores brasileiros foram quase unânimes ao declarar uma atitude proativa em relação ao ensino sobre o uso de dicionários. Entre 6 (seis) respostas válidas a respeito dessa questão, apenas 1 (um) professor declarou esperar o aparecimento de dúvidas para abordar o assunto. Os professores estrangeiros, por sua vez, apresentaram respostas que nos permitem notar a preferência, entre os respondentes, por uma postura mais reativa.

Além da predominância de uma atitude proativa, percebemos que o ensino sobre o uso do dicionário, entre os professores brasileiros respondentes, tende a ocupar os espaços e tempos típicos do que chamamos de rituais introdutórios dos cursos de língua, relacionados aos períodos de inícios de semestre ou ano letivo, dividindo atenção, por exemplo, com comentários e explicações introdutórias sobre o livro didático ou sobre a metodologia adotada para o curso.

6 Interpretamos que, nesse caso, trata-se da primeira vez que o professor leva o dicionário à sala de aula, deflagrando, portanto, uma atitude proativa. 
Cabe observar que os dados não permitiram estabelecer essa característica em relação aos professores estrangeiros.

\section{Considerações finais}

Os resultados obtidos em nossa pesquisa apontam, ainda que timidamente, para a definição de um perfil de professores de língua italiana como língua adicional, atuantes no início do século XXI, no Brasil e na Europa, predominantemente na Itália, que valoriza a utilização do dicionário e que concede lugar ao ensino sobre o uso desse recurso em suas aulas. De fato, a maioria dos professores respondentes declara ensinar sobre o uso dos dicionários.

Percebemos a predominância de uma atitude proativa, por parte dos professores respondentes brasileiros, no que diz respeito ao ensino do uso do dicionário. Isso quer dizer que a maioria desses docentes que decidem trabalhar com esse tema em suas aulas prefere fazê-lo de modo planejado, em oposição a uma postura reativa, em que a instrução sobre o uso do dicionário terá lugar em forma de feedback, quando do surgimento de dúvidas. Essa última, por sua vez, parece ser a postura dos professores estrangeiros, participantes da pesquisa.

Percebemos, enfim, uma tendência, entre os professores brasileiros, respondentes da investigação, a eleger os espaços e tempos típicos dos rituais introdutórios dos cursos de língua para ensinar sobre o uso do dicionário. Conforme acenamos, não foi possível observar esse aspecto entre os professores estrangeiros.

\section{Referèncias}

ATKINS, Beryl T. S.; KNOWLES, Frank E. Interim Report on the EURALEX/AПA Research Project Into Dictionary Use. 1990. Proceedings of Budapest '88, Budapest, Akademiai Kiadó. . Interim Report on the EURALEX/AПA Research Project Into Dictionary Use. 1990. In: MAGAY, Tamás; ZIGANY, Judith (Org.). BUDAPEST '88. Budapest. Proceedings, 04-09 set. 1988. Budapest, Akademiai Kiadó, 1988. apud CORDA, Alessandra; MARELLO, Carla. Lessico: Insegnarlo e impararlo. Perugia: Guerra Edizioni, 2004.

BÉJOINT, Henri. Tradition and Innovation in Modern English Dictionaries. Oxford: Oxford University Press, 1994 apud WELKER, Herbert Andreas. O uso de dicionários: panorama geral das pesquisas empíricas. Brasília: Thesaurus, 2006.

. Modern Lexicography. An Introduction. Oxford: Oxford University Press, 2000 apud WELKER, Herbert Andreas. O uso de dicionários: panorama geral das pesquisas empíricas. Brasília: Thesaurus, 2006.

BISHOP, G. Developing learner strategies in the use of dictionaries as a productive language learning tool. The Language Learning Journal, v. 22, n. 1, p. 58-62, ago. 2000. Disponível em: <https://doi. org/10.1080/09571730085200261> Acesso em: 20 fev 2018.

BROWN, James Dean; RODGERS, Theodore S. Doing Second Language Research. Oxford: Oxford University Press, 2002.

CARDUNER, Jessie. Productive dictionary skills training: what do language learners find useful? 
Language Learning Journal, Winter 2003, 28, p. 70-76

CUBILLO, M. C. C. Dictionary Use and Dictionary Needs of ESP Students: an Experimental Approach. In: International Journal of Lexicografhy, 15, 3, p. 206-228.

CHI, Man Lai Amy. Teaching dictionary skills in the classroom. In: FONTENELLE, T. et al. (Ed.). ACTES EURALEX '98. Proceedings... v. II, Liége: Université de Liége, Département d'Anglais et de Néerdlandais, 1998, p. 565-578.

CARVER, R. P. Percentage of unknown vocabulary words in text as a function of the relativy difficulty of the text: Implications for instruction. Journal of Reading Behavior, 26, 413-437, 1994 apud KODA, Keiko. Insights into Second Language Reading: a Cross-Linguistic Approach. Cambridge: Cambridge University Press, 2004.

CARVER, R. P. The cause of high and low reading achievement. Mahwah, Nj: Erlbaum, 2000. apud KODA, Keiko. Insights into Second Language Reading: a Cross-Linguistic Approach. Cambridge: Cambridge University Press, 2004.

CORDA, Alessandra; MARELLO, Carla. Lessico: Insegnarlo e impararlo. Perugia: Guerra Edizioni, 2004.

DELL'ISOLA, Regina L. Peret. A construção do sentido durante a leitura em Português LE. In: JÙDICE, Norimar (ORG.). Português Língua Estrangeira: leitura, produção e avaliação de textos.Niterói: Intertexto, 2000.

DIAS, Pedro. O uso do dicionário. English online. Portugal: Sapo - Universidade de Aveiro, S.D.

ERASMUS PROGRAMME. Erasmus Programme. Disponível em: <http://erasmusprogramme. com>. Acesso em: 21 junho 2018.

FINGER-KRATOCHVIL, C., CARVALHO, M. G. M. - O uso do dicionário como estratégia metacognitiva de aquisição lexical na leitura em mídia virtual e impressa. Revista Digital do Programa de Pós-Graduação em Letras da PUCRS, Porto Alegre, v. 9, n. 2, p. 295-309, jul.-dez. 2016.

FROMM, Guilherme. Dicionários em sala de aula: como aproveitá-los bem. In: FROMM, Guilherme; HERNANDES, Maria Célia Lima (Org.). Domínios de Linguagem III: Práticas Pedagógicas 2. 1. ed. São Paulo, 2003. v. 1, p. 41-50.

HU, M.; NATION, I. S. P. Unknown vocabulary density and reading comprehension. Reading in a Foreign Language, 18, 249-301, 2000 apud KODA, Keiko. Insights into Second Language Reading: a Cross-Linguistic Approach. Cambridge: Cambridge University Press, 2004.

HUDSON, T. Teaching Second Language Reading. Oxford: Oxford University Press, 2007.

KODA, Keiko. Insights into Second Language Reading: a Cross-Linguistic Approach. Cambridge: Cambridge University Press, 2004.

LARSEN-FREEMAN, Diane. Techniques and principles in language teaching. Oxford: Oxford University Press, 2004.

LEFFA, Vilson J. O dicionário eletrônico na construção do sentido em língua estrangeira. Cadernos de Tradução, Florianópolis, n. 18, p. 319-340, 2006.

. Questões de lexicografia pedagógica. In: XATARA, C., BEVILACQUA, Cleci Regina, HUMBLÉ, Philippe René Marie (Orgs.). Dicionários na teoria e na prática: como e para quem são feitos. São Paulo: Parábola Editorial, 2011. p. 123-132.

LUPPESCU, S.; DAY, R. R. Reading dictionaries and vocabulary learning. Language Learning, v43, 2, p. 263-87, 1993.

MATLIN, M. W. Psicologia cognitiva. 5. ed. Trad. Stella Machado. Rio de Janeiro: LTC, 2004.

MULLER, V. The use of dictionaries as a pedagogical ressource in the foreign language classroom. In: European Association for Lexicography - Euralex, 10, 2002, København, Denmark. Anais 
(on-line). København: Euralex, 2010. p. 717-721. Disponível em: <https://euralex.org/publications/the-use-of-dictionaries-as-a-pedagogical-ressource-sic-in-the-foreign-language-classroom/ $>$. Acesso em em: 10 maio 2018.

OXFORD, Rebecca. L. Language Learning Strategies: what every teacher should know. Boston: Heinle \& Heinle, 1990.

RICHARDS, J. C.; RODGERS, T. S. Approaches and Methods in Language Teaching. 2. ed. New York: Cambridge University Press, 2001.

SCHMITT, N. et al. The percentage of words known in a text and reading comprehension. The Modern Language Journal, v. 95, p. 26-43. 2011.

STRAUSS, A.; CORBIN, J. Pesquisa Qualitativa: técnicas e procedimentos para o desenvolvimento de teoria fundamentada. Porto Alegre: Artmed, 2008.

WARING, Rob. Oxford learner dictionaries: getting your students to use their dictionaries effectively. Japão: Oxford University Press., 2001.

WELKER, Herbert Andreas. O uso de dicionários: panorama geral das pesquisas empíricas. Brasília: Thesaurus, 2006.

WIDDOWSON, H. G. O ensino de línguas para a comunicação. Tradução de J. Carlos P. Almeida Filho. Campinas: Pontes, 1991.

ZUCCHI, A. M. T. O uso de dicionários na compreensão escrita em italiano. In: European Association for Lexicography - Euralex, 14, 2010, Leeuwarden/Ljouwert, The Netherlands. Anais (on-line). Leewarden: Euralex, 2010. p. 1152-1160 Disponível em: <https://euralex.org/publications/o-uso-de-dicionarios-na-compreensao-escrita-em-italiano-le/>. Acesso em: 10 de maio de 2018.

Recebido em: 01/09/2018

Aprovado em: 24/10/2018 
ANEXO I - Plano de aula com instruções sobre o dicionário integradas (CHI, 1998, p. 577)

Teaching Plan

\begin{tabular}{|c|c|c|c|c|}
\hline & & Contents & Dictionary skills being integrated & Work to do/Assignments \\
\hline $\begin{array}{l}\text { Wk7 } \\
14 / 10\end{array}$ & Les2 & $\begin{array}{l}\text { OIntroducing the steps involved in writing a research paper } \\
\text {-choosing a subject area } \\
\text {-narrowing down the topic } \\
\text {-doing tibrary search } \\
\text {-writing a central thesis } \\
\text {-forming a title } \\
\text { OIntroducing how to search for materials in a library } \\
\text { OSetting a central thesis } \\
\text { OUsing directive words to set title }\end{array}$ & $\begin{array}{l}\text { Introduce learner's dictionaries to assist } \\
\text { reading } \\
\text {-lcarner's vs general } \\
\text { •introducing special features found in } \\
\text { various learner's dictionaries }\end{array}$ & \\
\hline $\begin{array}{l}\text { Wk8 } \\
21 / 10\end{array}$ & Les2 & ORevising summary writing & $\begin{array}{l}\text {-Introduce typical arrangements of } \\
\text { dictionary entries } \\
\text {-Grammatical coding system } \\
\text {-Compounds and derivatives } \\
\text {-Language style - labeis and } \\
\text { collocations }\end{array}$ & $\begin{array}{l}\text { Bring to class photocopies of } \\
\text { written sources and present them } \\
\text { to the group for discussion on } \\
6 / 11 \text {, second lesson of Wk } 10\end{array}$ \\
\hline $\begin{array}{l}\text { Wk9 } \\
28 / 10\end{array}$ & LesI & $\begin{array}{l}\text { ORevising paraphrasing and style in writing } \\
2 \text { Writing quotations and bibliography } \\
\text { o Structuring a paper - Introduction, Body and Conclusion }\end{array}$ & $\begin{array}{l}\text { - Practise using learner's dictionaries - } \\
\text { finding directive words for in-text } \\
\text { references } \\
\qquad \text { Created with }\end{array}$ & $\begin{array}{l}\text { Bring draft of Paper I to class for } \\
\text { discussion on } 11 / 11 \text {. Submission } \\
\text { date for Paper } 1 \text { is } 14 / 11\end{array}$ \\
\hline
\end{tabular}

